\title{
Historical Atlas of Poland 2.0 - over 140 years of joint work of historians and cartographers
}

\author{
Katarzyna Słomska-Przech ${ }^{\mathrm{a}, *}$, Dawid Maciuszek ${ }^{\mathrm{a}}$, Aniela Rząsa ${ }^{\mathrm{a}}$, Tomasz Panecki ${ }^{\mathrm{a}}$ \\ ${ }^{a}$ Tadeusz Manteuffel Institute of History, Polish Academy of Sciences - kslomska@ihpan.edu.pl, dawidjanmaciuszek@gmail.com, \\ aniela.rzasa@gmail.com,tpanecki@ihpan.edu.pl \\ * Corresponding author
}

Keywords: atlas, historical cartography, hGIS, digital humanities, popularisation of knowledge

\begin{abstract}
:
The idea of developing a Historical Atlas of Poland (HAP) in the $16^{\text {th }}$ century dates back to the end of the $19^{\text {th }}$ century and the first General Congress of Polish Historians. However, the actual work on the project began after the Second World War. Since then generations of historians and cartographers have been working together on the Atlas, initially with traditional methods, and from the beginning of the 21 st century moving towards methods used in digital humanities and GIS. Therefore, one of the challenges of the 70-year series has been to maintain cartographic consistency when changing mapping methods.
\end{abstract}

It was planned to develop 9 volumes for all 18 palatinates of the Polish Crown, which covered an area of approximately 180,000 square kilometres. The main goal of the initiative was to reconstruct the settlement network, administrative borders, roads depicted on a base map (land cover, hydrography) based on topographic maps from the turn of the $18^{\text {th }}$ and $19^{\text {th }}$ centuries (Rutkowski 2018). Each volume of the series consists of text commentary and map series: the main map (scale 1:250,000, Figure 1), overview maps presenting ecclesiastical divisions of land, non-Catholic communities, distribution of landownership and major roads (scale 1:500,000), several city plans (scale 1:10,000).

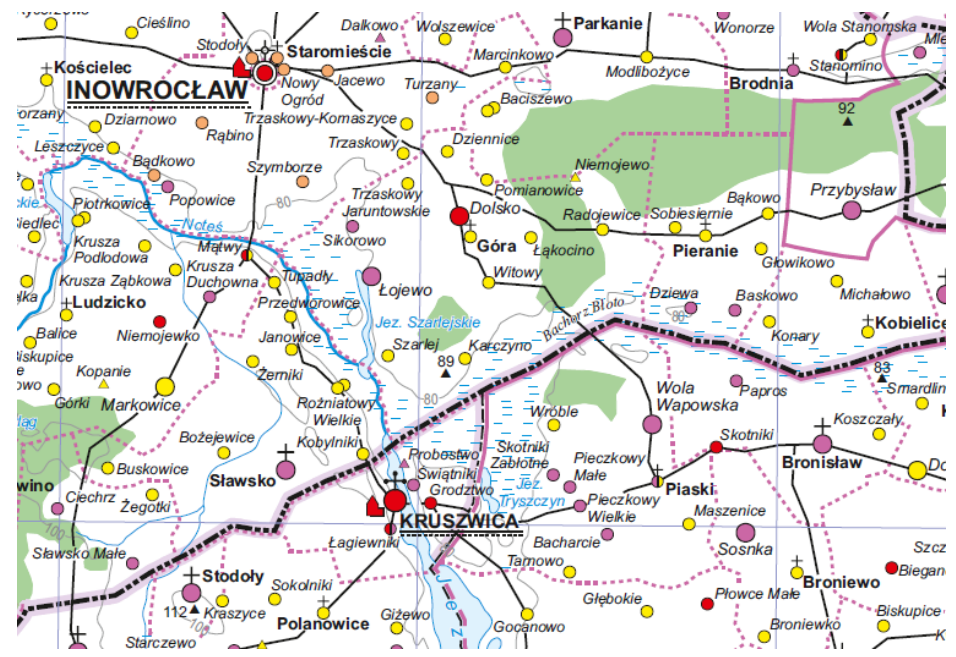

Figure 1. Fragment of a detailed map of Cuyavia in the 16 century.

The last volumes of the Historical Atlas of Poland, as well as a volume combining all the previous publications from this series will be published in 2021. We will also make the spatial database of the project available on the Internet, in the hope that it will serve the next generations of Polish history researchers. Nonetheless, the works are continued in the project Historical Atlas of Poland 2.0, which aims at building a stable repository for HAP data in accordance with the FAIR rules, as well as at popularisation of knowledge and research work carried out at the Tadeusz Manteuffel Institute of History PAS. The key element of collected data is the reconstruction of the complete (according to current knowledge) $16^{\text {th }}$ century settlement network. Our knowledge is derived from well-preserved $16^{\text {th }}$ century written sources, mainly tax registers. The location of the settlements is determined on the basis of retrogressive methods supplemented by other sources including field research. Tax registers are also a source of relevant knowledge of Ecclesiastical parish affiliation - the lowest administrative divisions at the time - which allowed us to draw parish borders. Data was edited and symbolised consistently throughout decades of the project. The preparation of a common database for the entire project required combining and harmonizing data from different volumes. Data collected in the pre-GIS era required integration 
and re-edition. It was necessary, inter alia, to correct the location of settlement points from old volumes, adjust roads and forest borders, and improve the hierarchy of ecclesiastical divisions. After that layers and symbolization are exported respectively to .shp and .sld formats. One of the core components of the Historical Atlas of Poland 2.0 project is a geoportal. Our aim is to develop a platform for publishing and sharing HAP data and to build a community of engaged users. Being as open and user-friendly as possible will help us to fulfil the goal of popularizing the data and knowledge gathered in decades of work and research on HAP. The platform that has been chosen for the project is GeoNode (Figure 2) - an open-source framework serving as a base for building geospatial content management systems and spatial data infrastructures (Corti et al. 2019). Its rich features intended for data publishing, organizing them in structures, and presenting on a map supports well our goal of creating a geoportal and data repository implementing FAIR rules. Furthermore, the HAP 2.0 geoportal will contain a robust search tool to explore the resources and a community module letting users create accounts, publish their own datasets and actively work with the repository.
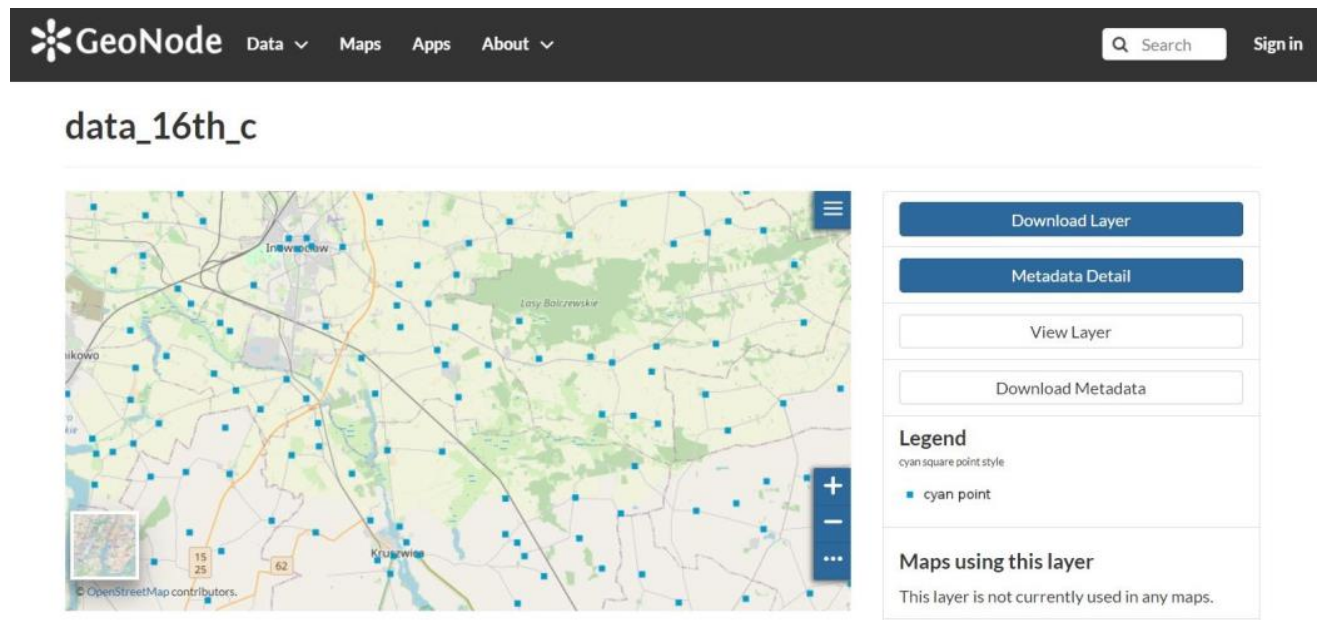

Figure 2. GeoNode layer preview displaying settlements in the 16 century.

In conclusion, in 2021, the project which has started in the 1950s will be finished. Finally, the idea presented by historians at the end of the $19^{\text {th }}$ century will be completed and transferred into the digital world. We believe that the geoportal will contribute to extending access to spatial, historical data for the needs of state administration, cultural institutions, education, and scientific work. Moreover, we hope that the popularization part of the project will improve the social perception of humanities research.

\section{Acknowledgements}

This research was funded by the Ministry of Science and Higher Education, Poland, grant number SONP/SP/466930/2020, "Atlas Historyczny Polski 2.0”.

\section{References}

Corti, P., Bartoli, F., Fabiani, A., Giovando, C., Kralidis, A. T., Tzotsos, A., 2019. GeoNode: an open source framework to build spatial data infrastructures. PeerJ Preprints 7:e27534v1 https://doi.org/10.7287/peerj.preprints.27534v1 (Accessed online 21 May 2021).

Rutkowski, H., Work on the historical atlas of the sixteenth-century Poland, „Polish Cartographical Review“ 4 (50), 2018, pp. 223-231. 